\title{
RESPOSTA DO FEIJ OEIRO A RELAÇÕES VARIÁVEIS ENTRE CÁLCIO E MAGNÉSIO NA CAPACIDADE DE TROCA DE CÁTIONS DE LATOSSOLOS ${ }^{(1)}$
}

\author{
E. L. OLIVEIRA ${ }^{(2)} \&$ M. S. PARRA ${ }^{(2)}$
}

\begin{abstract}
RESUMO
Com o objetivo de avaliar a influência da relação entre Ca e Mg na CTC do solo sobre o rendimento do feijoeiro, foi realizado um experimento em casa de vegetação, em vasos com $3,5 \mathrm{dm}^{3}$ de amostras de um Latossolo Vermel ho distrófico psamítico-LVdp e um Latossolo Vermelho aluminoférrico típico-LVat. Os tratamentos, dispostos em blocos casualizados, com seis repetições, constaram das seguintes relações molares entre $\mathrm{Ca}$ e $\mathrm{Mg:}$ 1/2, 1, 2, 4, 6 e 8. Três repetições foram colhidas no florescimento e as demais mantidas até à colheita dos grãos. Os rendi mentos da matéria seca do feijoei ro obtida no estádio de flor escimento foram semelhantes nos dois solos, mas os rendi mentos de grãos obtidos no L Vat foram $\mathbf{4 0} \%$ superiores aos obtidos no LVdp. Entretanto, estas variáveis não foram significativamente influenciadas pelas diferentes relações $\mathrm{Ca}$ :Mg no solo. As concentrações de Ca e Mg e suas relações no tecido da matéria seca do feijoeiro, obtida no florescimento, apresentaram estreita relação com os teores e relações destes elementos no solo. Os resultados obtidos mostraram que em solos com teores adequados de $\mathrm{Ca}$ e $\mathrm{Mg}$ trocáveis, a relação entre eles é de importância secundária para o desenvolvimento e rendimento do feijoeiro.
\end{abstract}

Termos de indexação: Phaseolus vulgaris, relação Ca/Mg, saturação por bases, calagem.

(1) Trabalho apresentado no XXVIII Congresso Brasileiro de Ciência do Solo, Londrina, 2001. Recebido para publicação em dezembro de 2001 e aprovado em junho de 2003.

(2) Pesquisador do Instituto Agronômico do Paraná - IAPAR. Rod. Celso Gacia Cid, km 375, Caixa Postal 481, CEP 86047-902 Londrina (PR). E-mails: eloveira@iapar.br; maurosp@iapar.br 


\title{
SUMMARY: COMMON BEAN RESPONSE TO VARIABLE PROPORTIONS OF CALCIUM AND MAGNESIUM IN THE CATION EXCHANGE CAPACITY OF OXISOLS
}

\begin{abstract}
A greenhouse experiment was carried out to evaluate the effect of the $\mathrm{Ca} / \mathrm{Mg}$ ratio in the cation exchange capacity on common bean growth. Samples of a typic ferric al umi num Red Latosol (LVat) and a psamitic dystrophic Red Latosol (LVdp), both Haplortox (U.S. Soil Taxonomy) in pots containing $3.5 \mathrm{dm}^{3}$ of soil were treated with Ca:Mg ratios of $1 / 2,1$, 2, 4, 6 and 8. Theexperiment was arranged in a complete y randomized block design with six replications. Three repl ications were harvested at the flowering stage and the rest kept until thegrain harvest. Dry matter weight, obtained at the fl owering stage, was similar in both soils; the grain yield in the LVat, however, was $40 \%$ higher than the one obtained in the LVdp. Nevertheless, thesevariables werenot si gnificantly affected by the $\mathrm{Ca} / \mathrm{Mg}$ ratios. $\mathrm{Ca}$ and $\mathrm{Mg}$ contents in the tissue and their ratios during flowering were closely related to exchangeablesoil $\mathrm{Ca}$ and $\mathrm{Mg}$ contents and $\mathrm{Ca} / \mathrm{Mg}$ ratios. Results showed that in soils with suitable levels of exchangeable $\mathrm{Ca}$ and $\mathrm{Mg}$, the $\mathrm{Ca} / \mathrm{Mg}$ ratio is of secondary importance for the development and grain yield of common bean.
\end{abstract}

Index terms: Phaseol us vulgaris, $\mathrm{Ca} / \mathrm{Mg}$ ratio, base saturation, liming.

\section{NTRODUÇÃO}

A acidez natural ou induzida pelo uso inadequado do solo ainda constitui uma das principais limitações para obtenção de altas produtividades das culturas no estado do Paraná. Oliveira et al. (1997), analisando os resultados do levantamento de reconhecimento dos solos do Paraná (EMBRAPA, 1984; IAPAR, 1984) mostraram que $61 \%$ da área do Estado era ocupada por sol os que apresentavam caráter álico ou distrófico, indicando a necessidade de aplicação de calcário para obtenção de rendimentos satisfatórios das culturas.

Os métodos de recomendação de calcário empregados no Paraná são baseados, anal ogamente, no conceito de suficiência de nutriente desenvolvido por Bray (1944; 1945). No entanto, os agentes da assistência técnica têm levantado que o uso deste conceito, aliado ao emprego contínuo de calcário dolomítico, está promovendo um estreitamento das relações entre os teores de cálcio e magnésio trocáveis que pode limitar a produtividade das culturas. Nestes casos, o emprego do conceito de relação entrea saturação por cátions bási cos do solo, proposto por Bear \& Toth (1948), tem sido indicado como alternativa para amenizar os possíveis prejuízos à produtividade das culturas. Neste conceito, a capacidade de troca de cátions do solo deve ser preenchida com $65 \%$ de Ca, $10 \%$ de Mg e $5 \%$ de $\mathrm{K}$, resultando em relações Ca:Mg, Ca:K e Mg:K , respectivamente, de6,5:1 13:1 e2:1. Contudo, grande número detrabal hos que relatam a aplicação deste conceito apresentam resultados contraditórios.

Freqüentemente, segundo os resultados apresentados, grande variação na saturação por cátions na CTC do solo não influiu ou teve pequena influência no rendimento de diversas espécies cultivadas (McLean \& Carbonell, 1972; Lierop et al ., 1979; Liebhardt, 1981; Fox \& Piekielek, 1984). De maneira semel hante, a relação entre $\mathrm{Ca}$ e $\mathrm{Mg}$ não apresentou influência no rendimento das culturas (F oy \& Barber, 1958; Simson et al., 1979; Muchovej et al., 1986; Oliveira, 1993). Grant \& Racz (1987) sal ientaram ainda que as concentrações de $\mathrm{Ca}$ eMg na solução do solo foram mais importantes para o crescimento de cevada do que as relações entre estes cátions na CTC do solo. Por outro lado, Oliveira et al. (1994) observaram efeitos significativos do aumento da saturação de Ca na CTC do solo no rendimento de matéria seca de mudas de cafeeiro. Silva (1980) obteve os melhores rendimentos de matéria seca de milho com a relação 3:1 entre Ca e Mg em solos com 60 e $70 \%$ da CTC saturada com Ca, enquanto Mostafa \& Ulrich (1976) concluíram que a relação $\mathrm{Ca}: \mathrm{Mg}$ pode ser um fator limitante na nutrição de Ca para beterraba-açucareira.

Em decorrência de resultados relativamente contraditórios e da preocupação constante da assistência técnica com efeitos negativos da baixa relação $\mathrm{Ca} / \mathrm{Mg}$ na produtividade das culturas, desenvolveu-se um experimento para avaliar os efeitos da relação Ca:Mg no rendimento e concentração destes cátions no feijoeiro.

\section{MATERIAL E MÉTODOS}

O experimento foi desenvolvido em casa de vegetação com amostras de um Latossol o Vermel ho distrófico psamítico ( $L V d p)$ e de um Latossolo Vermelho aluminoférrico típico (LVat). As 
características químicas e granul ométricas dos sol os determinadas, respectivamente, segundo métodos descritos por Pavan et al. (1992) eE MBRAPA (1979), encontram-se no quadro 1. As amostras de solo foram coletadas na camada de $0-20 \mathrm{~cm}$, tamizadas em peneira de $6 \mathrm{~mm}$, homogeneizadas esecas ao ar.

Os tratamentos constaram da aplicação de uma mistura de $\mathrm{CaCO}_{3}$ e $\mathrm{MgCO}_{3}$, calculada para manter uma relação molar entre Ca e Mg de 1/2, 1, 2, 4, 6 e 8 e elevar a saturação por bases no solo para $80 \%$. As misturas, juntamente com quantidades de $\mathrm{KCl}$ suficientes para elevar a concentração de K trocável para $5 \%$ da CTC de cada solo e 50 e $100 \mathrm{mg} \mathrm{kg}^{-1}$ de fósforo na forma de $\mathrm{Ca}\left(\mathrm{H}_{2} \mathrm{PO}_{4}\right)_{2}$ em pó, respectivamente, para $L V d p$ e $L V$ at, foram aplicadas em subamostras de $30 \mathrm{~kg}$ de solo seco. As subamostras foram homogeneizadas manual mente e umedecidas com água destilada, suficiente para atingir $80 \%$ deágua no sol o submetida a uma tensão de 0,01 MPa. As subamostras, assim preparadas, foram incubadas em sacos plásticos e mantidas em temperatura ambiente por um período de dois meses e meio. Durantea incubação, os sacos foram abertos semanalmente e o solo revolvido para promover aeração das amostras incubadas.

I mediatamente antes do preparo dos vasos para instalação do experimento, foram retiradas amostras do material incubado para análise química de rotina, conforme Pavan et al. (1992), e deCa eM g na solução do solo. Para este procedimento, amostras de $60 \mathrm{~cm}^{3}$ de solo seco e moído (peneira de $2 \mathrm{~mm}$ ) foram acondicionadas em seringas hipodérmicas, saturadas com água destilada e incubadas por uma período de $24 \mathrm{~h}$. A pós este período, foi obtido um extrato mediante filtragem com sucção, o qual foi considerado como solução do solo. Le Roux \&

Quadro 1. Características químicas e granulométricas dos solos utilizados nos experimentos

\begin{tabular}{|c|c|c|}
\hline Característica & LVat & LVdp \\
\hline $\mathrm{pH}\left(\mathrm{CaCl}_{2} 0,01 \mathrm{~mol} \mathrm{~L}^{-1}\right)$ & 4,10 & 4,00 \\
\hline Al $\left(\mathrm{mmol}_{\mathrm{c}} \mathrm{dm}^{-3}\right)$ & 16,7 & 11,7 \\
\hline $\mathrm{H}+\mathrm{Al}\left(\mathrm{mmol}_{\mathrm{c}} \mathrm{dm}^{-3}\right)$ & 129,2 & 58,4 \\
\hline $\mathrm{Ca}\left(\mathrm{mmol}_{\mathrm{c}} \mathrm{dm}^{-3}\right)$ & 19,3 & 7,1 \\
\hline $\mathrm{Mg}\left(\mathrm{mmol}_{\mathrm{c}} \mathrm{dm}^{-3}\right)$ & 9,2 & 2,3 \\
\hline $\mathrm{K}\left(\mathrm{mmol}_{\mathrm{c}} \mathrm{dm}^{-3}\right)$ & 1,4 & 1,6 \\
\hline CTC $\left(\mathrm{mmol}_{\mathrm{c}} \mathrm{dm}^{-3}\right)$ & 159,1 & 69,4 \\
\hline V (\%) & 19 & 15 \\
\hline$P\left(\mathrm{mg} \mathrm{dm}^{-3}\right)$ & 2,9 & 9,2 \\
\hline C orgânico (g kg-1) & 31,5 & 16,4 \\
\hline Areia $\left(\mathrm{g} \mathrm{kg}^{-1}\right)$ & 15 & 76 \\
\hline Silte $\left(\mathrm{g} \mathrm{kg}^{-1}\right)$ & 14 & 2 \\
\hline Argila (g kg-1) & 71 & 22 \\
\hline
\end{tabular}

Sumner (1967) mostraram que este período de incubação é suficiente para o equilíbrio entre a fase líquida e sólida do solo. O Ca e o Mg foram determinados por espectroscopia de emi ssão atômica - ICP. As análises foram efetuadas em triplicata.

$\mathrm{Na}$ semeadura do feijoeiro no experimento, as subamostras incubadas foram separadas em porções equivalentes a 3,5 dm $\mathrm{dm}^{3}$ de sol o seco. Como adubação básica, for am aplicados em cada vaso $300 \mathrm{mg}$ de $\mathrm{N}$ $\left(\mathrm{NH}_{4} \mathrm{NO}_{3}\right), 400$ mgdeP $\left[\mathrm{Ca}\left(\mathrm{H}_{2} \mathrm{PO}_{4}\right)_{2}\right]$ com 1,0 <grânulos $<2,0 \mathrm{~mm}, 400 \mathrm{mg}$ de $\mathrm{K}\left(\mathrm{K}_{2} \mathrm{SO}_{4}\right)$ e $300 \mathrm{mg}$ de $\left(\mathrm{K}_{2} \mathrm{SO}_{4}\right.$ $+\mathrm{CaSO}_{4} \cdot 2 \mathrm{H}_{2} \mathrm{O}+\mathrm{MgSO}_{4} \cdot 7 \mathrm{H}_{2} \mathrm{O}$ ). Foram, também, aplicados $100 \mathrm{~mL}$ de uma solução que continha $2,0 \mathrm{mg}$ de $\mathrm{B}\left(\mathrm{H}_{3} \mathrm{BO}_{3}\right) ; 3,0 \mathrm{mg}$ de $\mathrm{Mn}\left(\mathrm{MnSO}_{4} \cdot \mathrm{H}_{2} \mathrm{O}\right)$; $3,0 \mathrm{mg}$ de $\mathrm{Zn}\left(\mathrm{Zn} \mathrm{SO}_{4} .7 \mathrm{H}_{2} \mathrm{O}\right) ; 0,2 \mathrm{mg}$ de $\mathrm{Cu}$ (CuSO4.5 $\left.\mathrm{H}_{2} \mathrm{O}\right) ; 0,1 \mathrm{mg}$ de $\mathrm{Mo}\left[\left(\mathrm{NH}_{4}\right)_{6} \mathrm{Mo}_{7} \mathrm{O}_{24} \cdot 4 \mathrm{H}_{2} \mathrm{O}\right]$ e10 $\mathrm{mL}$ de uma solução com $5,0 \mathrm{mg} \mathrm{Fe}\left(\mathrm{FeCl}_{3} \cdot 6 \mathrm{H}_{2} \mathrm{O}\right)$. As porções foram umedecidas com água destilada suficiente para atingir a tensão de 0,01 MPa, homogeneizadas manualmentee acondicionadas em vasos de poli propileno com capacidade de $4 \mathrm{~L}$. F oram utilizadas 10 sementes da variedade IAPAR $81 \mathrm{em}$ cada vaso, efetuando-se, posteriormente, o desbaste, deixando-se três plantas por vaso.

Cada tipo desolo constituiu-se em um experimento isolado, sendo os tratamentos dispostos em um delineamento experimental de blocos casualizados com seis repetições. As plantas de três repetições foram col hidas por ocasião do florescimento do feijoeiro, aproximadamente 42 dias após a emergência, e as demais mantidas atéà colheita de grãos.

Durante o desenvolvimento das plantas, a umidade dos solos foi ajustada, diariamente, mediante pesagem dos vasos e adição de água destilada até atingir a tensão deágua equivalentea 0,01 MPa. Durantea execução desse procedimento, foi efetuada uma rotação entre os bl ocos e dos vasos dentro dos blocos. Como adubação complementar, foram aplicados, parcel adamente, atéo florescimento, 590 e 323 mg vaso $^{-1}$, respectivamente, de $\mathrm{N}$ e K nas formas de $\mathrm{NH}_{4} \mathrm{NO}_{3}$ e $\mathrm{KNO}_{3}$. $\mathrm{Nos}$ vasos que continham LVat, parte do $\mathrm{N}$ foi suprido por $\left(\mathrm{NH}_{4}\right)_{2} \mathrm{HPO}_{4}$ para fornecer também $200 \mathrm{mg}$ vaso ${ }^{-1}$ de $P$. Nos vasos mantidos atéà col heita de grãos, foram ainda adicionadas, parceladamente, $690 \mathrm{mg}$ vaso $^{-1}$ de $\mathrm{N}$, em ambos os solos, e $200 \mathrm{mg}^{2}$ vaso $^{-1}$ de $\mathrm{P}$, no LVat, nas formas de $\mathrm{NH}_{4} \mathrm{NO}_{3} \mathrm{e}\left(\mathrm{NH}_{4}\right)_{2} \mathrm{HPO}_{4}$.

A parte aérea das plantas colhidas em pleno florescimento foi seca em estufa com circulação forçada de ar, durante $72 \mathrm{~h}$ a $65^{\circ} \mathrm{C}$, pesada e moída em moinho equipado com naval has e peneira de $2 \mathrm{~mm}$. Em amostras destes materiais, foram determinadas as concentrações de macro e micronutrientes, conforme método descrito por Miyazawa et al. (1992). Nos grãos colhidos, foram determinadas a massa ea umi dade, calculando-se a massa final dos grãos com umidade padronizada a $13 \%$. 
Os dados foram analisados estatisticamente pelos procedimentos proc reg (SAS, 1989). Admitiu-se $p \leq 0,05$ como limite para significância estatística dos coeficientes de determinação e estimadores dos parâmetros dos modelos.

\section{RESULTADOS E DISCUSSÃO}

As misturas de $\mathrm{CaCO}_{3}$ e $\mathrm{MgCO}_{3}$ não el evaram os teores de Ca e Mg trocáveis e a saturação por bases dos solos para os val ores previamenteestabel ecidos, indicando uma reação parcial dos compostos. Entretanto, as relações Ca:Mg determinadas foram próximas às previstas (Quadro 2). Em geral, tem sido freqüente a observação de valores menores de saturação por bases e de concentrações de Ca e Mg trocáveis determinados analiticamente do que os estabelecidos previamente, tanto para resultados obtidos com incubação de solo em laboratório com carbonatos ou cal cário (Oliveira,1993; Costa et al., 1996), quanto para experimentos com aplicação de calcário no campo (Morelli et al., 1992; Caires \& Rosolem, 1993; Oliveira et al., 1997). As razões para esse comportamento são, geral mente, atribuídas não só ao tempo insuficiente para o equilíbrio das reações químicas dos carbonatos e ao poder de tamponamento dos solos, mas também às eventuais perdas de Ca e Mg por lixiviação e exportação dos elementos pelas col heitas.

Ao contrário da semel hança entre os rendimentos médios de matéria seca obtidos no florescimento nos dois solos, or rendimento médio de grãos no $L V$ at foi $40 \%$ superior ao obtido no LVdp (Figura 1). Esta diferença, entretanto, não pode ser atribuída às condições nutricionais do feijoeiro, visto que as concentrações de nutrientes na matéria seca obtida no florescimento (Quadro 3) foram semel hantes entre os sol os e, com exceção do $\mathrm{N}$ nos dois sol os e do $\mathrm{Cu}$ no LVdp que estavam levemente abaixo, os demais nutrientes encontravam-se dentro dos limites de suficiência para a cultura, tomando-se, como referência, os teores de nutrientes determinados na terceira fol ha madura do feijoeiro no início da floração, conforme descrito por Malavol ta et al. (1989). Observou-se, ainda, uma estreita correlação entre a produção de grãos de feijão e o rendimento de matéria seca do feijoeiro no florescimento, obtida no LVat $\left(r=0,87^{*}\right)$, bem como ausência de correlação entreestas variáveis no L Vdp ( $r=0,19^{\text {ns }}$ ).

A relação Ca:Mg no solo não influenciou significativamente os rendimentos de matéria seca das plantas do feijoeiro no estádio de florescimento e de grãos, ainda que estas variáveis apresentassem val ores mais elevados com a relação Ca:M g em torno de 2,0 principalmente no LVat.

Os resultados mostraram comportamento semelhante aos relatados por Simson et al. (1979), Fox \& Piekielek (1984), Muchovej et al. (1986) e Oliveira (1993) que verificaram a ausência de efeito de uma ampla variação na relação $\mathrm{Ca}$ :Mg do sol o no rendimento das culturas. Para Key et al. (1962), na existência de quantidades suficientes de $\mathrm{Ca}$ e Mg, a relação entre estes cátions, desde que superior a 1:1, não tinha influência no rendimento de soja e milho.

Por outrolado, Oliveira et al. (1994) verificaram efeitos significativos da relação Ca:Mg em diferentes

Quadro 2. Análises químicas dos solos efetuadas por ocasião da instalação do experimento

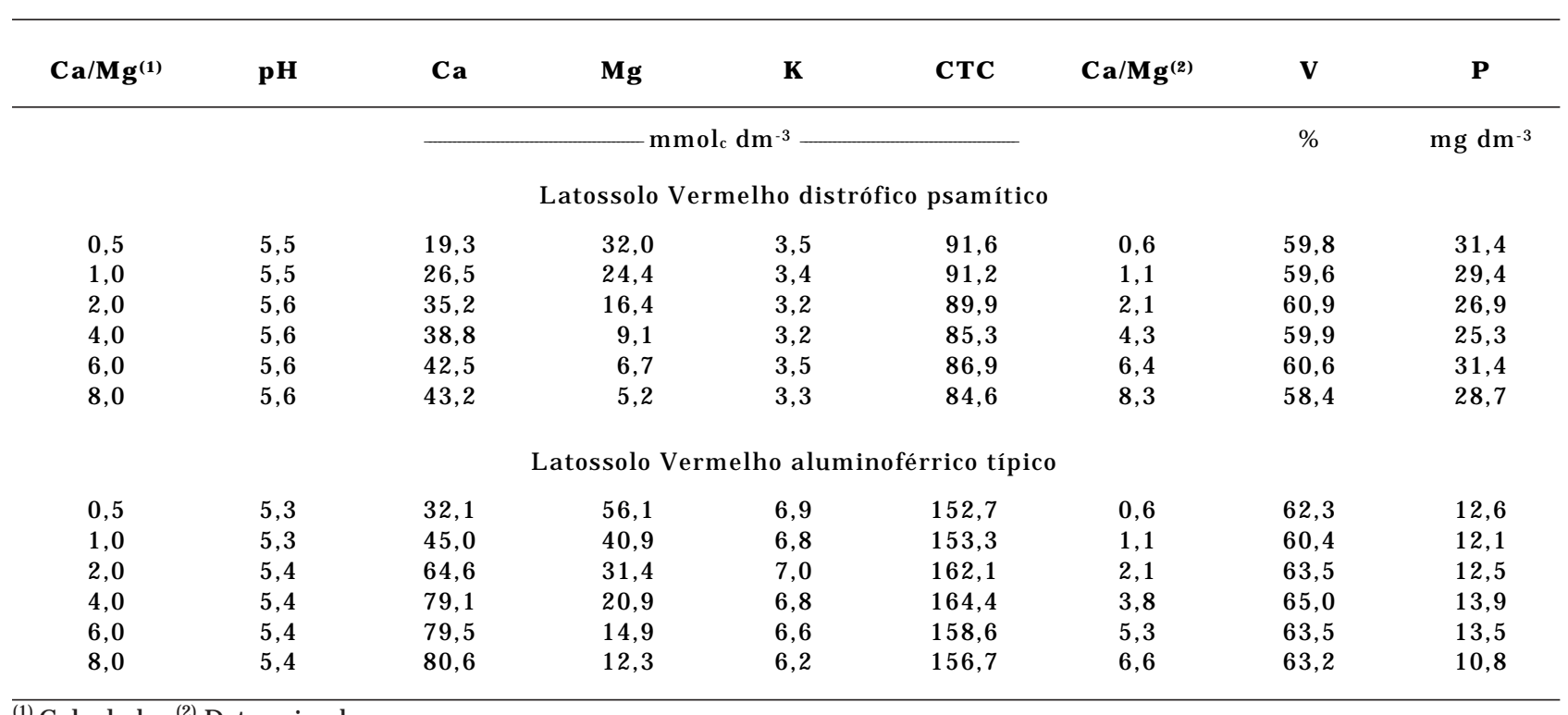

${ }^{(1)}$ Calculada. ${ }^{(2)}$ Determinada. 
níveis de CTC do solo, no desenvol vimento de mudas de cafeeiro; Silva (1980) relatou que os melhores rendimentos de milho, cultivado em vasos que continham solos típicos de cerrado, foram obtidos
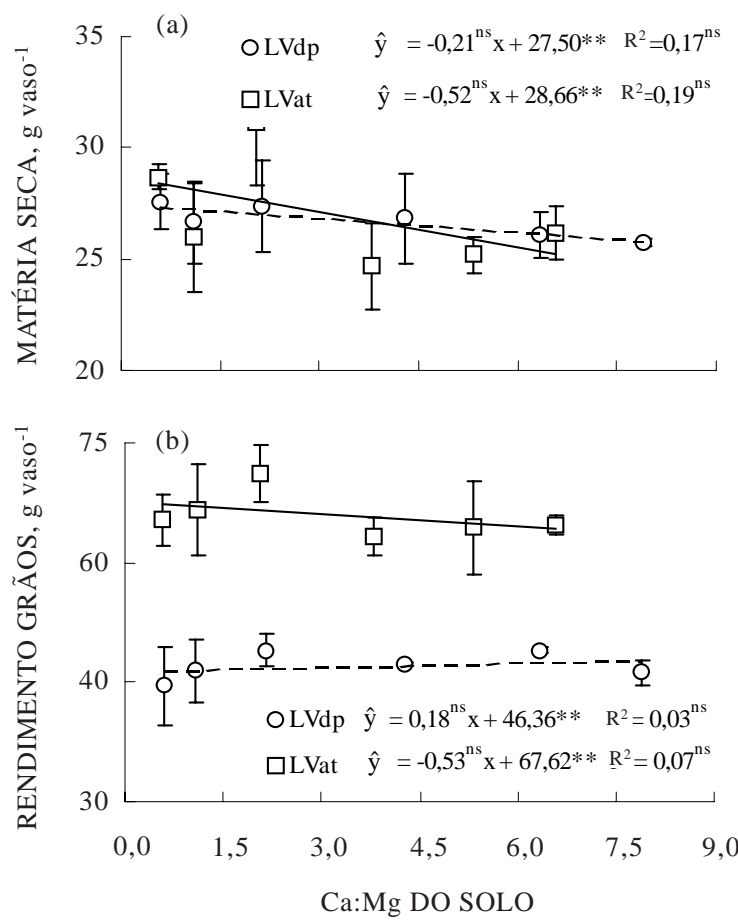

Figura 1. Rendimentos de matéria seca obtida no florescimento do feijoeiro (a) e de grãos (b) considerando a relação $\mathrm{Ca}: \mathrm{Mg}$ do solo. ${ }^{\mathrm{ns}}$, **, respectivamente, não-significativo esignificativo pelo teste " $t$ " Student $p \leq 0,01$. com relação a Ca:Mg de 3:1; Munoz Hernandez \& Silveira (1998) observaram efeito significativo da relação Ca:M g em solo com 50 por cento de saturação por bases no rendimento de matéria seca de milho, enquanto Mostafa \& UIrich (1976 ) concluíram que a relação Ca:Mg pode ser limitante na nutrição de Ca para beterraba açucareira. Estas contradições indicam que a importância da relação Ca:Mg pode estar relacionada com a espécie cultivada e com o potencial de fornecimento destes nutrientes pelo solo.

As concentrações de Ca e de Mg na matéria seca da parte aérea obtida no florescimento do feijoeiro foram significativamenteinfluenciadas pela relação Ca:Mg do solo (Figura 2). Os acréscimos nas concentrações de $\mathrm{Ca}$ e os decréscimos nas de $\mathrm{Mg}$ são decorrentes da variação simultânea entre as concentrações de Ca e Mg trocáveis no solo, necessária para o preenchimento da quantidade fixa de cargas da CTC do solo. Resultados semel hantes foram observados em experimentos similares, desenvolvidos com diferentes espécies e condições experimentais (Key et al., 1962; Silva, 1980; Oliveira, 1993; Munoz Hernandez \& Silveira, 1998).

De maneira análoga ao comportamento das concentrações de $\mathrm{Ca}$ e $\mathrm{Mg}$, as relações entre estes cátions no tecido da matéria seca da parte aérea do feijoeiro foram igualmente influenciadas pelas relações Ca:Mg dos solos (Figura 3). O modelo de resposta foi semel hanteaos obtidos por Lierop et al. (1979), para cebola, e por Oliveira (1993), para milho, e indica a maior facilidade de absorção de $\mathrm{Mg}$ do que de Ca. Entretanto, observou-se uma diferença de magnitude entre a relação $\mathrm{Ca}: \mathrm{Mg}$ no tecido das espécies citadas e a correspondente no solo, a qual

Quadro 3. Concentração de nutrientes em tecido de feijoeiro obtido no florescimento

\begin{tabular}{|c|c|c|c|c|c|c|c|c|}
\hline Relação Ca/Mg & $\mathbf{N}$ & $\mathbf{P}$ & $\mathbf{K}$ & $\mathbf{s}$ & $\mathrm{Cu}$ & $\mathbf{Z n}$ & B & Mn \\
\hline \multicolumn{9}{|c|}{$-\mathrm{g} \mathrm{kg}^{-1}$} \\
\hline \multicolumn{9}{|c|}{ Latossolo Vermel ho distrófico psamítico } \\
\hline 0,61 & 24,8 & 2,52 & 27,6 & 2,24 & 6 & 35 & 32 & 66 \\
\hline 1,08 & 24,1 & 2,57 & 28,8 & 2,14 & 8 & 35 & 29 & 56 \\
\hline 2,14 & 24,4 & 2,63 & 26,3 & 2,31 & 6 & 35 & 29 & 63 \\
\hline 4,28 & 24,1 & 2,73 & 27,1 & 2,23 & 7 & 37 & 31 & 64 \\
\hline 6,35 & 24,8 & 2,64 & 28,0 & 2,30 & 7 & 36 & 32 & 73 \\
\hline 8,30 & 24,6 & 2,58 & 27,6 & 2,15 & 7 & 34 & 27 & 70 \\
\hline \multicolumn{9}{|c|}{ Latossolo Vermel ho aluminoférrico típico } \\
\hline 0,57 & 25,0 & 2,87 & 27,6 & 2,22 & 10 & 23 & 29 & 72 \\
\hline 1,10 & 28,2 & 2,72 & 30,5 & 2,00 & 11 & 24 & 25 & 78 \\
\hline 2,05 & 23,1 & 2,68 & 26,4 & 1,94 & 11 & 22 & 26 & 63 \\
\hline 3,79 & 28,7 & 2,62 & 28,0 & 2,01 & 11 & 23 & 26 & 82 \\
\hline 5,32 & 29,8 & 2,79 & 30,1 & 2,05 & 12 & 24 & 26 & 79 \\
\hline 6,57 & 29,1 & 2,64 & 28,4 & 1,95 & 12 & 24 & 24 & 77 \\
\hline
\end{tabular}



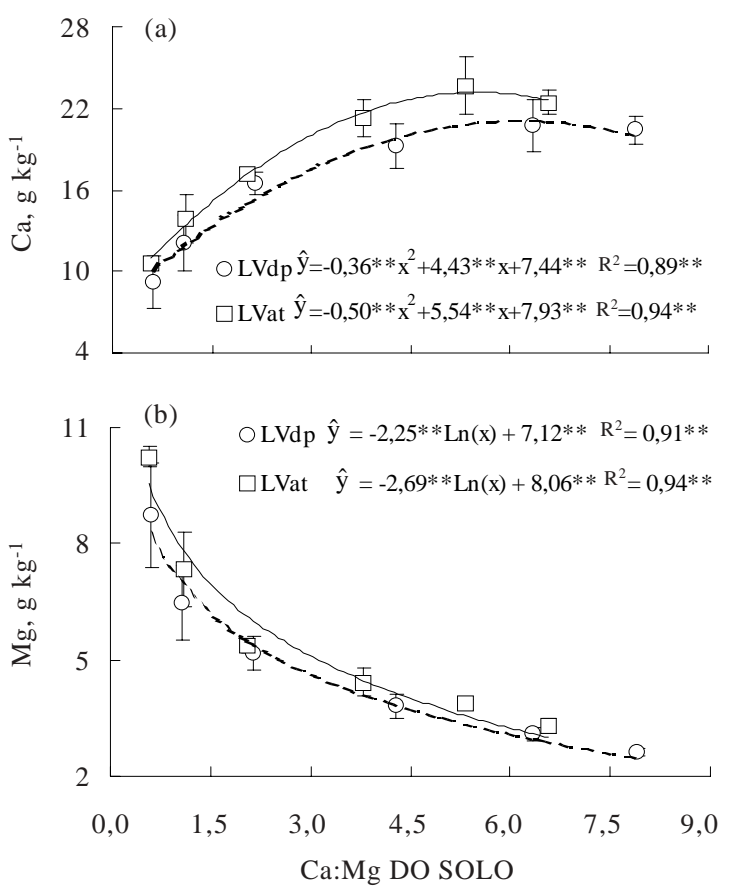

Figura 2. Concentrações de Ca (a) e Mg (b) na matéria seca do feijoeiro obtida no florescimento considerando a relação Ca:Mg do solo. ${ }^{\mathrm{ns}}, * *$, respectivamente, não-significativo e significativo pelo teste " $t$ " Student $p \leq 0,01$.

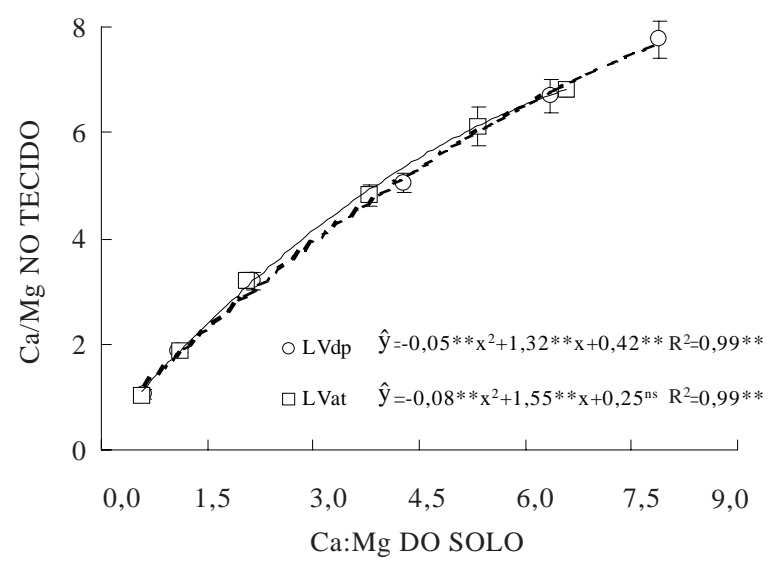

Figura 3. E feito da relação Ca:Mg do solo na relação entre as concentrações destes cátions na matéria seca do feijoeiro obtida no florescimento. ns, $* *$, respectivamente, não-significativo e significativo pelo teste " $t$ " Student $p \leq 0,01$.

pode ser atribuída às diferenças entre as espécies em termos de acúmulo destes nutrientes no tecido foliar, para satisfazer suas necessidades metabólicas.

A ausência de efeito da relação Ca:Mg do solo e, por conseguinte, dos elementos isolados nos rendimentos de matéria seca do feijoeiro e de grãos de feijão, bem como da relação entre estes e a concentração de Ca e Mg no tecido vegetal, aliada a teores dos demais nutrientes considerados suficientes, indica que a diferença de rendimentos de grãos de feijão entre os solos pode ser devida a fatores extranutricionais, visto que os solos apresentavam características distintas.

Ao contrário da redução observada nas concentrações de $\mathrm{Mg}$ de acordo com o aumento da relação Ca:Mg no solo, as concentrações de Ca e Mg no tecido foram positivamente relacionadas com os teores absol utos de Ca eMg trocáveis eapresentaram diferenças entre solos (Figuras 4 e 5). Embora as concentrações médias de Ca e Mg na matéria seca do feijoei ro obtido no $L V$ at fossem levementesuperiores às observadas no LVdp, os resultados mostraram que, para obter concentrações de $\mathrm{Ca}$ ou $\mathrm{Mg}$ semel hantes na matéria seca do feijoeiro nos dois solos, mantendose a mesma relação Ca:Mg, as concentrações de Ca ou Mg trocáveis no LVat eram consideravelmente superiores às verificadas no LVdp.

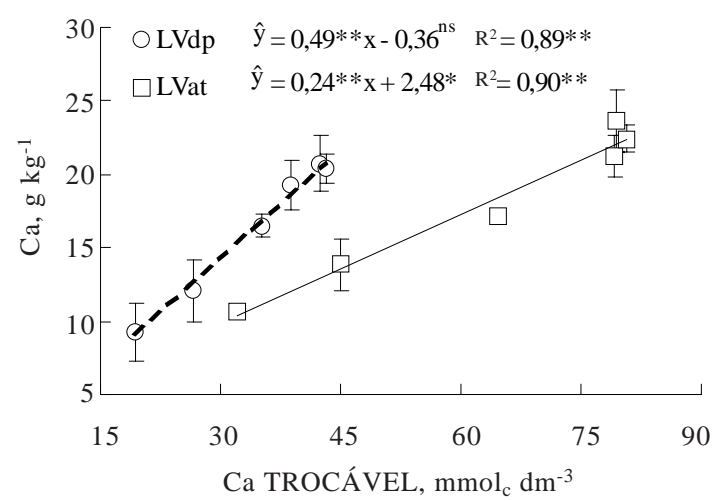

Figura 4. Relação entre a concentração de Ca na matéria seca de feijoeiro e a concentração de Ca trocável do solo. ${ }^{\text {ns }}$ não-significativo; * $\mathbf{e}^{* *}$, respectivamente, significativo pelo teste " $\mathrm{t}$ " Student $p \leq 0,05$ e $p \leq 0,01$.

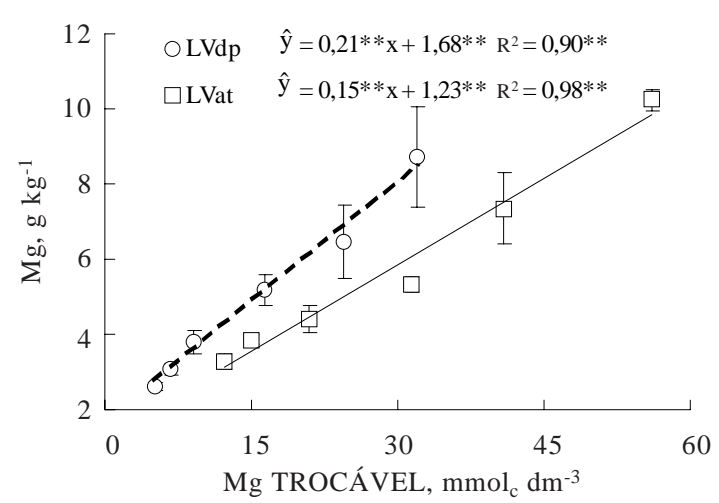

Figura 5. Relação entre a concentração de Mg na matéria seca de feijoeiro e a concentração de Mg trocável do solo. ${ }^{\mathrm{ns}}$,**, respectivamente, não-significativo e significativo pelo teste " $\mathrm{t}$ " Student $p \leq 0,01$. 


\section{Quadro 4. Relação entre cátions na solução e trocáveis nos solos}

\section{Equação linear}

\begin{tabular}{|c|c|}
\hline \multicolumn{2}{|l|}{ Latossolo Vermelho distrófico psamítico } \\
\hline $\mathrm{C} \mathrm{a}_{\text {solução }}=11,91 \mathrm{Ca}$ trocavel $-6,71$ & $0,99 * *$ \\
\hline $\mathrm{Mg}_{\text {solução }}=7,86 \mathrm{Mg}$ trocavel $+1,19$ & $0,99 * *$ \\
\hline $\mathrm{Ca}$ solução $/ \mathrm{Mg}_{\text {solução }}=1,11 \mathrm{Ca}$ trocavel $/ \mathrm{Mg}$ trocavel $-0,04$ & $0,99 * *$ \\
\hline \multicolumn{2}{|l|}{ Latossolo Vermel ho aluminoférrico típico } \\
\hline $\mathrm{Ca}_{\text {solução }}=3,18 \mathrm{Ca}$ trocavel $-3,29$ & $0,98 * *$ \\
\hline $\mathrm{Mg}_{\text {solução }}=1,55 \mathrm{Mg}$ trocavel $+3,10$ & $0,88 * *$ \\
\hline $\mathrm{Ca} a_{\text {solução }} / \mathrm{Mg}_{\text {solução }}=1,04 \mathrm{Ca}$ trocavel $/ \mathrm{Mg}$ trocavel $-0,10$ & $0,99 * *$ \\
\hline
\end{tabular}

E mbora Németh et al. (1970) tenham demonstrado uma estreita correlação entre as concentrações de $\mathrm{Ca}$ e Mg trocável e suas respectivas concentrações na solução, independentemente da textura dos sol os estudados, os resultados obtidos no presente trabal ho mostraram acentuadas diferenças entre o LVdp e o LVat para estas correlações (Quadro 4). Os resultados evidenciam que o LVdp apresentava 2,0 vezes mais $\mathrm{Ca}$ e 1,8 vez mais $\mathrm{Mg}$ na solução do que o LVat e justificam a necessidade de concentrações de Ca e Mg trocáveis no LVat mais elevadas para manter concentrações semelhantes destes nutrientes na matéria seca da parte aérea do feijoei ro obtida nos dois solos.

\section{CONCLUSÃO}

A ausência de resposta do feijoeiro às variações na relação $\mathrm{Ca}: \mathrm{Mg}$ do solo, tanto no rendimento de matéria seca no estádio de florescimento quanto na produção de grãos, não permitiu o estabelecimento de uma relação $\mathrm{Ca}: \mathrm{Mg}$ no sol o mais apropriada para o cultivo desta espécie.

\section{AGRADE CIMENTOS}

Os autores agradecem aos Técnicos Agrícolas J uarez Cassiano e Pedro L. Stringuetta, a ajuda operacional na execução do experimento.

\section{LITE RATURA CITADA}

BEAR, F.E. \& TOTH, S.J . Influence of Ca on availability of other soil cations. Soil Sci., 65:69-75, 1948.

BRAY, R.H. Soil-plant relationships: I. The quantitative relation of exchangeable $\mathrm{K}$ to crop yields and to crop response to potash additions. Soil Sci., 58:305-324, 1944.
BRAY, R.H. Soil-plant relationships: II. Balanced fertilizer use through soil tests for K and P. Soil Sci., 60:463-473, 1945.

CAIRES, E.F. \& ROSOLEM, C.A. Calagem em genótipos de amendoim. R. Bras. Ci. Solo, 17:193-202,1993.

COSTA, A.; PARRA, M.S. \& TOMAZ, M.L. Comparação de métodos para determinação da necessidade de calagem de um Latossolo Vermelho-Escuro álico da região de Ponta Grossa. Arq. Biol. Tecnol., 39:333-342,1996.

EMPRESA BRASILEIRA DE PESQUISA AGROPECUÁRIA EMBRAPA. Serviço Nacional de Levantamento e Conservação do Solo, Rio de J aneiro. Levantamento de Reconhecimento dos Sol os do Paraná. Londrina, 1984. 413p. (Boletim Técnico, 57)

EMPRESA BRASILEIRA DE PESQUISA AGROPECUÁRIA EMBRAPA. Serviço Nacional de Levantamento e Conservação do solo, Rio de J aneiro. Manual de métodos de análise de solo. Rio de J aneiro, 1979. Não paginado.

FOX, R.H. \& PIEKIELEK, W.P. Soil magnesium level, corn (Zea mays L.) yield, and magnesium uptake. Comm. Soil. Sci. Plant. Anal., 15:109-123, 1984.

FOY, C.D. \& BARBER, S.A. Magnesium and corn yield in two acid Indiana soils. Soil Sci. Soc. Am. Proc., 22:145-148,1958.

FUNDAÇÃO INSTITUTO AGRONÔMICO DO PARANÁ IAPAR. Projeto Especial de Levantamento de Solos. Levantamento e reconhecimento dos solos do estado do Paraná. Londrina, 1984. 413p. (Boletim Técnico, 16)

GRANT, C.A. \& RACZ, G.J. The effect of $\mathrm{Ca}$ and $\mathrm{Mg}$ concentrations in nutrient solution on the dry matter yield and $\mathrm{Ca}, \mathrm{Mg}$ and $\mathrm{K}$ content of barley (Hordeum vulgare $\mathrm{L}$ ). Can. J. Soil Sci., 67:857-865,1987.

KEY, J .L.; KURTZ, L.T. \& TUCKER, B.B. Influence of ratio of exchangeable cal cium-magnesium on yield and composition of soybeans and corn. Soil Sci., 4:265-271, 1962.

Le ROUX, J . \& SUMNER, M.E. Studies on the soil solution of various Natal soils. Geoderma, 1:125-130, 1967.

LIEBHARDT, W.C. The basic cation saturation ratio concept and lime and potassium recomendations on Delaware's coastal plain soils. Soil Sci. Soc. Am. J ., 45:544-549, 1981.

LIEROP, W. van; MARTEL, Y.A. \& CESCAS, M.P. Onion response to lime on acid Histisols as affected by $\mathrm{Ca} / \mathrm{Mg}$ ratios. Soil Sci. Soc. Am. Proc., 43:1172-1177, 1979.

MALAVOLTA, E.; VITTI, G.C. \& OLIVEIRA, S.A. Avaliação do estado nutricional das plantas: princípios e aplicações. Piracicaba, Associação Brasileira para Pesquisa da Potassa e do F osfato, 1989. 201p.

MCLEAN, E.O. \& CARBONELL, M.D. Calcium, magnesium, potassium saturation ratios in two soils and their effects upon yields and nutrient contents on german millet and alfafa. Soil Sci. Soc. Am. Proc., 36:927-930, 1972.

MIYAZAWA, M.; PAVAN, M.A. \& BLOCH, M.F.M. Análise química de tecido vegetal. Londrina, Instituto Agronômico do Paraná, 1992.17p. (Circular, 74)

MORELLI, J.L.; DALBEN, A.E.; ALMEIDA, J.O.C. \& DEMATTÊ, J L.L.I. Calcário e gesso na produtividade da cana-de-açúcar e nas características de um Latossolo de textura média álico. R. Bras. Ci. Solo, 16:187-194, 1992. 
MOSTAFA, M.A.E. \& ULRICH, A. Interaction of calcium and magnesium in nutrition of intact sugarbeets. Soil Sci., 121:16-20, 1976.

MUCHOVEJ, R.M.C.; BORGES, A.C.; NOVAIS, R.F. \& THIEBAUT, T.J .L. Effect of liming levels and Ca:Mg ratios on yields, nitrogen content and nodulation of soybeans grown in acid cerrado soil. J . Soil Sci., 37:235-240, 1986.

MUNOZ HERNANDEZ, R.J . \& SILVEIRA, R.I. Efeito da saturação por bases, relações Ca:Mg no solo e níveis de fósforo sobre a produção de material seco enutrição mineral de milho (Zea mays, L.). Sci. Agric., 55:79-85, 1998.

NÉMETH, K.; MENGEL, K. \& GRIMME, H. The concentration of $\mathrm{K}, \mathrm{Ca}$ and $\mathrm{Mg}$ in the saturation extract in relation to exchangeable K, Ca and Mg. Soil Sci., 109:179-185, 1970.

OLIVEIRA, E.F.; PAVAN, M.A. \& CHAVES, J.C.D. Respostas das mudas de cafeeiro ao equilíbio entre cátions trocáveis em solos com cargas variáveis. Arq. Biol. Tecnol., 37:973979, 1994.
OLIVEIRA, E.L. Rendimento de matéria seca e absorção de cálcio e magnésio pelo milho em função da relação cálcio/ magnésio no solo. R. Bras. Ci. Solo, 17:383-388,1993.

OLIVEIRA, E.L.; PARRA, M.S. \& COSTA, A. Resposta da cultura de milho, em um Latossolo Vermelho-Escuro álico, à calagem. R. Bras. Ci. Solo, 21:65-70, 1997.

PAVAN, M.A.; BLOCH, M.F.; ZEMPULSKI, H.C.; MIYAZAWA, M. \& ZOCOLER, D.C. Manual de análise química de solo e controle de qualidade. Londrina, Instituto Agronômico do Paraná, 1992. 38p. (Circular, 76)

SAS INSTITUTE, SAS/STAT, User's Guide. Version 6, 4.ed. Cary, 1989. v.2. 846p.

SILVA, J .E. Balanço de cál cio e magnésio e desenvol vimento de milho em solos de cerrado. Pesq. Agropec. Bras., 15:329333, 1980.

SIMSON, C.R.; COREY, R.B. \& SUMNER, M.E. Effect of varying $\mathrm{Ca}: \mathrm{Mg}$ ratios on yield and composition of corn (Zea mays) and alfafa (Mendicago sativa). Comm. Soil Sci. Plant Anal., 19:153-162, 1979. 